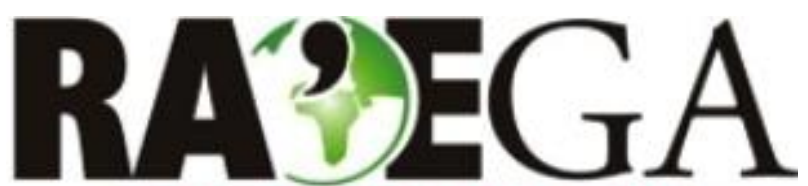

O ESPACCO GEOGRÁFICO EM ANÁLISE

\title{
SENSITIVIDADE FLUVIAL DA DRENAGEM PRINCIPAL DA BACIA HIDROGRÁFICA DO RIO SAGRADO - SERRA DO MAR PARANAENSE
}

\section{FLUVIAL SENSITIVITY OF MAIN DRAINAGE OF THE SAGRADO RIVER WATERSHED - SERRA DO MAR PARANAENSE \\ Monica Kleina ${ }^{1}$ e Leonardo José Cordeiro dos Santos ${ }^{2}$}

\section{RESUMO}

A sensitividade fluvial permite reconhecer pontos sujeitos às mudanças na rede de drenagem, identificadas por meio das forças de resistência (capacidade do sistema em resistir a uma alteração do estado inicial) e perturbação (aplicações de energias, como clima, interferências bióticas e antrópicas). Diante do exposto, o presente trabalho tem como objetivo determinar a sensitividade fluvial nas principais drenagens que compõem a bacia hidrográfica do rio Sagrado, localizada em Morretes, na Serra do Mar paranaense. Para obtenção dos resultados, tornou-se necessária a identificação dos estilos e ajustes fluviais, concentração de erosão, conectividade fluvial e evolução da ocupação da terra na bacia. Os dados foram sobrepostos e analisados, evidenciando que as maiores perturbações foram localizadas nos rios Sagrado e Sambaqui, principalmente próximas às planícies, classificadas como alta sensitividade. Diferentemente, rios margeados pelas altas declividades da Serra do Mar, recobertos por vegetação em estágio médio/avançado, situam-se locais com pouca probabilidade de mudanças, sendo denominadas como baixa sensitividade. Assim conclui-se que os terços de rios localizados em planícies possuem poucas resistências e muitas alterações no uso da terra, enquanto que nas altas declividades, em vales fluviais confinados e parcialmente confinados, a sensitividade apresenta-se baixa.

PALAVRAS-CHAVE: Resistências; Perturbações; Mudanças; Sistema fluvial.

\section{ABSTRACT}

The fluvial sensitivity allows to recognize points subject to changes in the drainage network, identified by the resistance forces (ability of the system to withstand a change of the initial state) and disturbance (energy applications such as climate, biotic and anthropic interference). Thus, the research's objective is to map the fluvial sensitivity in the major rivers that compose the Sagrado River watershed, located in Morretes, Serra do Mar, Paraná State. In order to obtain the results, it was necessary to identify the style and fluvial adjustments, erosion concentration, fluvial connectivity and land use evolution in the basin. The data were overlapped and confronted, evidencing that the major disturbances were located in Sagrado and Sambaqui rivers, especially near the plains areas, classified as high sensitivity. In contrast, rivers bordered by high slopes of the Serra do Mar, covered with vegetation in medium/advanced stage, are situated places of probability of minor changes, being named as low sensitivity. So it is concluded that thirds of rivers located in plains have low resistance and a lot of changes in land use, whereas in high declivity, in confined and partially confined fluvial valleys, the sensitivity appears low.

KEY-WORDS: Resistance; Disturbance; Changes; Fluvial system.

\footnotetext{
${ }^{1}$ Universidade Federal do Paraná, Curitiba/PR, e-mail: monicakleina@gmail.com

${ }^{2}$ Universidade Federal do Paraná, Curitiba/PR, e-mail: santos@ufpr.br
} 


\section{SENSITIVIDADE FLUVIAL DA DRENAGEM PRINCIPAL DA BACIA HIDROGRÁFICA DO RIO SAGRADO - SERRA DO MAR PARANAENSE}

\section{INTRODUÇÃO}

$\mathrm{Na}$ atualidade a geomorfologia fluvial coloca-se entre os temas mais pesquisados na Geomorfologia, o que pode ser comprovado em inúmeras publicações, no âmbito nacional e internacional (2001-2015), (SALGADO et al., 2008; OLIVEIRA e SALGADO, 2013; SALGADO e LIMOEIRO, 2017).

Ab'Saber (1957); Bigarella e Mousinho (1965); Christofoletti (1969); Fernandez (1990); Stevaux (1993); Fontes (2002); Zancopé et al., (2006; 2007); Bayer e Carvalho (2008); Carvalho (2009); Rocha (2010) e Marçal (2013) são alguns dos autores que realizaram pesquisas no país referentes à dinâmica e mudanças das formas fluviais, enquanto que Davis (1889); Bernard e Major (1963); Coleman e Gagliano (1965); Shumm (1968); Chorley e Kennedy (1971); Newson e Large (2006) e Rice et al., (2009) são alguns entre vários autores internacionais que trabalharam com essa temática.

Christofoletti (1969) evidencia que as pesquisas que envolvem a análise da rede hidrográfica auxiliam na compreensão de muitas questões geomorfológicas, responsáveis pela esculturação da paisagem.

Para Chorley e Kennedy (1971), a fisiografia fluvial é composta por uma rede complexa de elementos que se relacionam, na qual destacam-se dois principais: a morfologia dos rios, planícies e encostas, e o efeito cumulativo da interação água/sedimentos. A relação deste último com a paisagem modifica a rede de drenagem, podendo originar feições erosivas, deposicionais ou de alterações na configuração fluvial (sinuosidade).

Dentre os diversos estudos relacionados às alterações fluviais, a sensitividade vem crescendo e se destacando no âmbito nacional e internacional. Os trabalhos pioneiros de Brunsden e Thornes (1979); Brunsden (1993; 1996; 2001); Phillips (2009); Fryirs et al., (2009); Souza (2014); Souza et al., (2014) e Souza e Corrêa (2012; 2015), forneceram as bases conceituais e de aplicação desse método, permitindo a realização de diagnósticos para o planejamento ambiental e ecossistemas fluviais.
A sensitividade fluvial procura identificar os pontos sujeitos às mudanças, que superam as resistências do sistema, geradas por meio das forças de perturbação. A resistência é a capacidade do sistema em resistir a uma alteração do estado inicial após a aplicação de uma força de perturbação (BRUNSDEN e THORNES, 1979; MATTOS e PEREZ FILHO, 2004). Essas forças significam aplicações de energias no sistema, como interferências bióticas e antrópicas, que modificam as fisionomias originais da paisagem (BRUNSDEN, 2001).

Para compreender a sensitividade, é importante entender a proposição de estabilidade da paisagem, sendo uma função de distribuição temporal e espacial de forças de resistência e perturbação (BRUNSDEN, 1996). A partir do instante que o sistema passa a ter respostas perceptíveis à mudança, ele se desestabilizará, e provocará modificações no ambiente fluvial (BRUNSDEN e THORNES, 1979). A função da sensitividade é demostrar quais setores fluviais encontram-se mais perturbados e assim identificar os locais que necessitam de intervenções para a recuperação das áreas degradadas.

Uma área que vem sofrendo com constantes mudanças na paisagem é a bacia hidrográfica do rio Sagrado (Figura 1), com 137,7 $\mathrm{km}^{2}$, localizada no município de Morretes, na Serra do Mar paranaense. Paula (2010) constatou que esta bacia possui alto grau de antropização, se destacando como a principal responsável pelo assoreamento da baía de Antonina (PR), com contribuição anual de 4.777 toneladas de sedimentos.

Partindo do princípio da elevada produção de sedimentos constatada na área, o objetivo do trabalho foi identificar a sensitividade fluvial nos principais rios da bacia hidrográfica do rio Sagrado, a fim de reconhecer as forças de resistências e perturbações no sistema.

A área em questão está inserida na Unidade Morfoescultural Serra do Mar (MINEROPAR, 2001), na qual destacam-se as unidades do Complexo Gnáissico-Migmatítico, com mais de $50 \%$ da área da bacia, como 


\section{SENSITIVIDADE FLUVIAL DA DRENAGEM PRINCIPAL DA BACIA HIDROGRÁFICA DO RIO SAGRADO - SERRA DO MAR PARANAENSE}

também a grande presença de sedimentos recentes na planície de inundação (PAULA e NOWATZKI, 2009).

Os autores também relatam ainda que a declividade nas regiões de serras é muito alta, o que provoca movimentos de massa, enquanto que nas planícies é muito baixa, descrevendo esses ambientes como deposicionais e com elevada suscetibilidade ao acúmulo de sedimentos.

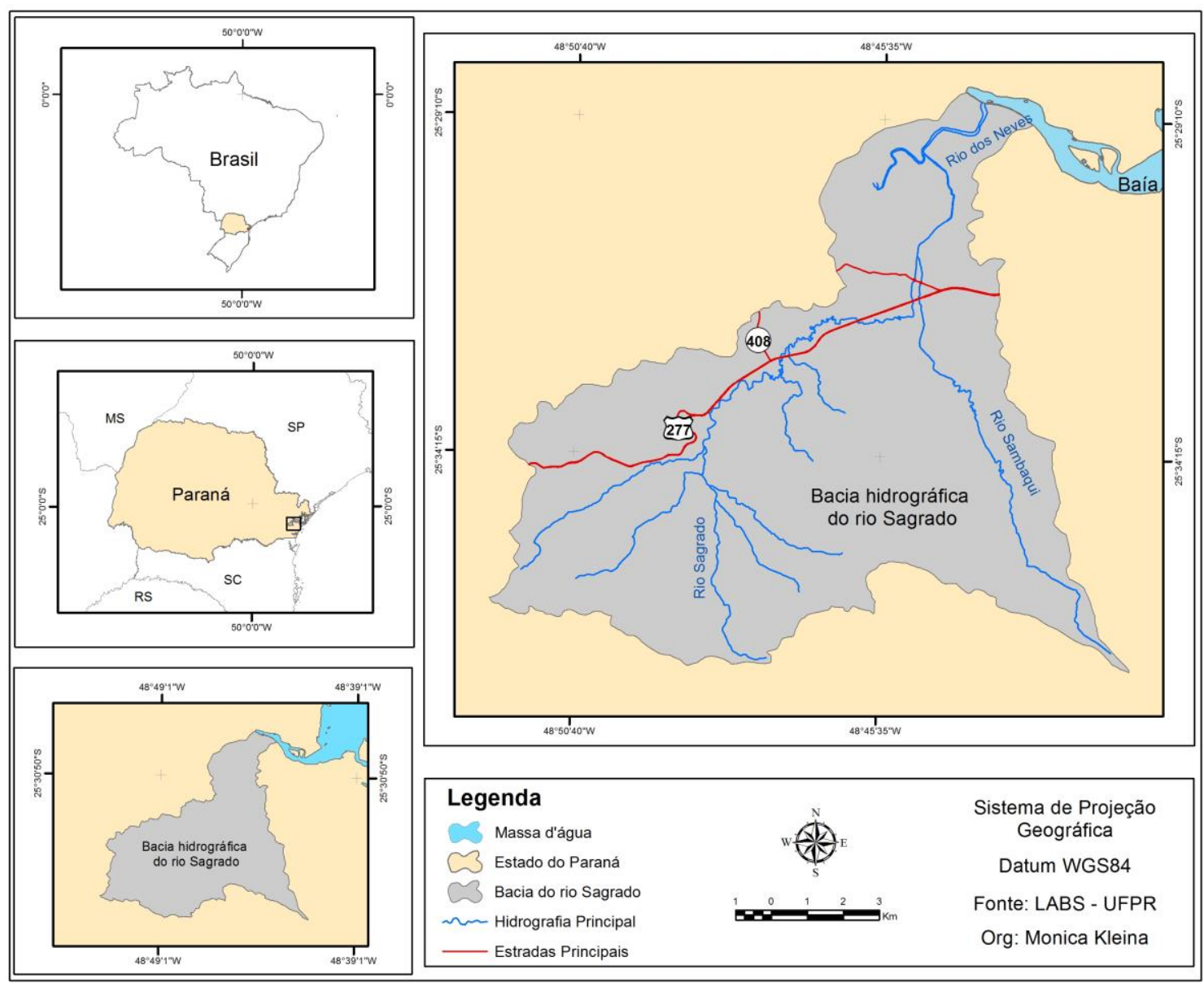

Figura 01 - Localização da bacia hidrográfica do rio Sagrado inserida dentro da área de drenagem da baía de Antonina e Paranaguá. Fonte: Os autores

\section{MATERIAIS E MÉTODOS}

Para este trabalho foi aplicado o método denominado de sensitividade (BRUNSDEN e THORNES, 1979), que tem por objetivo definir as forças impostas ao sistema e a probabilidade de uma mudança. O fluxograma representado pela Figura 2 ilustra as diferentes etapas da pesquisa. 
KLEINA, M. e SANTOS, L.J.C.

\section{SENSITIVIDADE FLUVIAL DA DRENAGEM PRINCIPAL DA BACIA HIDROGRÁFICA DO RIO SAGRADO - SERRA DO MAR PARANAENSE}

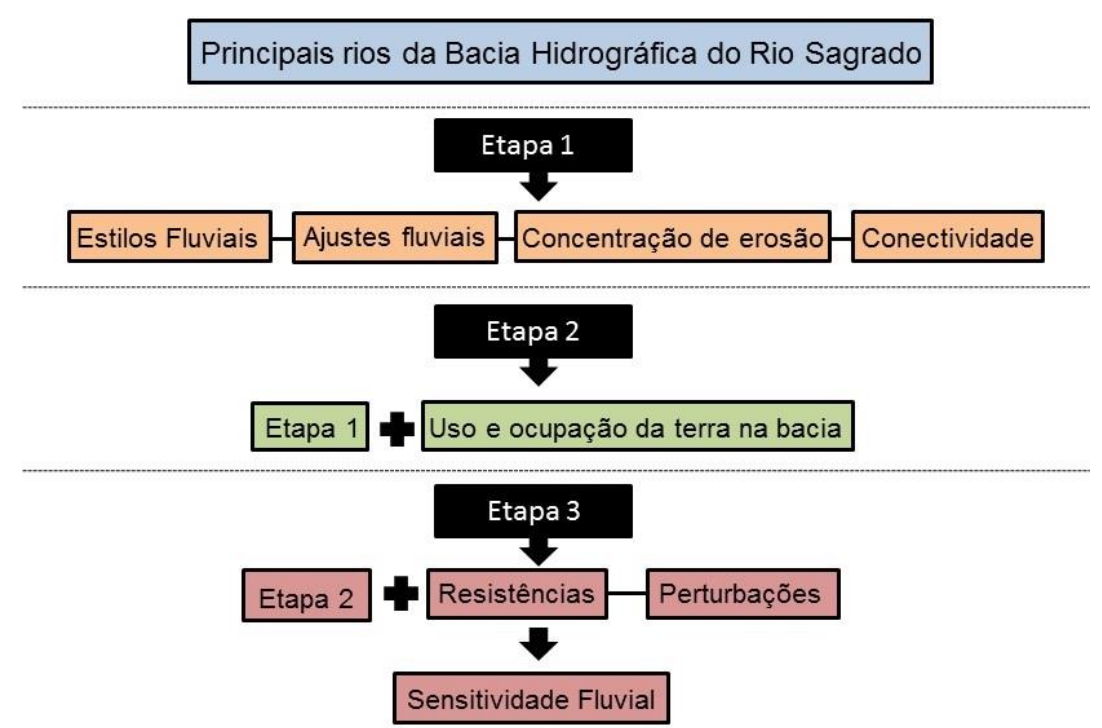

Figura 02 - Fluxograma simplificado da metodologia utilizada. Fonte: Os autores

O método consiste no desenvolvimento de três etapas: a primeira refere-se à identificação das características fluviais, como mudanças na sinuosidade (ajustes) e erosão; a segunda trata da análise dos resultados obtidos na etapa 1 , relacionados a evolução do uso e ocupação da terra na bacia; e por fim, a etapa 3 consiste na classificação dos trechos fluviais, definidos como rios perturbados ou de alta sensitividade e baixa resistência (alterações aceleradas), ou rios resistentes e de baixa sensitividade (pouca alteração fluvial e no uso e ocupação da terra).

O objeto de estudo foram os rios Sagrado, Sambaqui, dos Neves, Canhemborá, Ribeirão Fundo e Pitinga. Os critérios para a seleção destes canais fluviais foram suas dimensões em relação ao comprimento e a largura (maiores drenagens), condizentes com a escala das imagens de satélite para interpretação, utilizadas nos mapeamentos.

No que se refere a etapa 1 da pesquisa, o Estilo Fluvial (EF) é um método criado por Brierley e Fryirs (2002; 2005), aplicado no Brasil em diversas pesquisas, dentre elas aquelas desenvolvidas por Lima (2010); Peixoto et al., (2010); Ribeiro et al., (2011); Souza (2012); Souza e Correa (2012); Kleina (2013); Kleina et al., (2014) e Souza Maia e Souza (2016).

Os critérios utilizados no mapeamento dos EFs foram as feições de depósito (ilhas e barras), os tipos de vale, segundo a classificação de Lima (2010), assim como a sinuosidade, definida por Kellerhals (1976). A imagem de satélite utilizada na interpretação dos dados foi uma RapidEye, ano de 2012, com resolução espacial de cinco metros no modo pancromático e de dez metros no modo multiespectral, pertencente ao Laboratório de Biogeografia e Solos (LABS) da Universidade Federal do Paraná (UFPR).

Os ajustes fluviais, descritos em Kleina (2016), permitiram identificar mudanças longitudinais e laterais dos canais fluviais (Figura 3) por meio de uma análise temporal. Para isso, mapearam-se (por vetorização) os principais rios que compõem a bacia, nos anos de 1954, 1980, 1996, 2006 e 2012. 


\section{SENSITIVIDADE FLUVIAL DA DRENAGEM PRINCIPAL DA BACIA HIDROGRÁFICA DO RIO SAGRADO - SERRA DO MAR PARANAENSE}

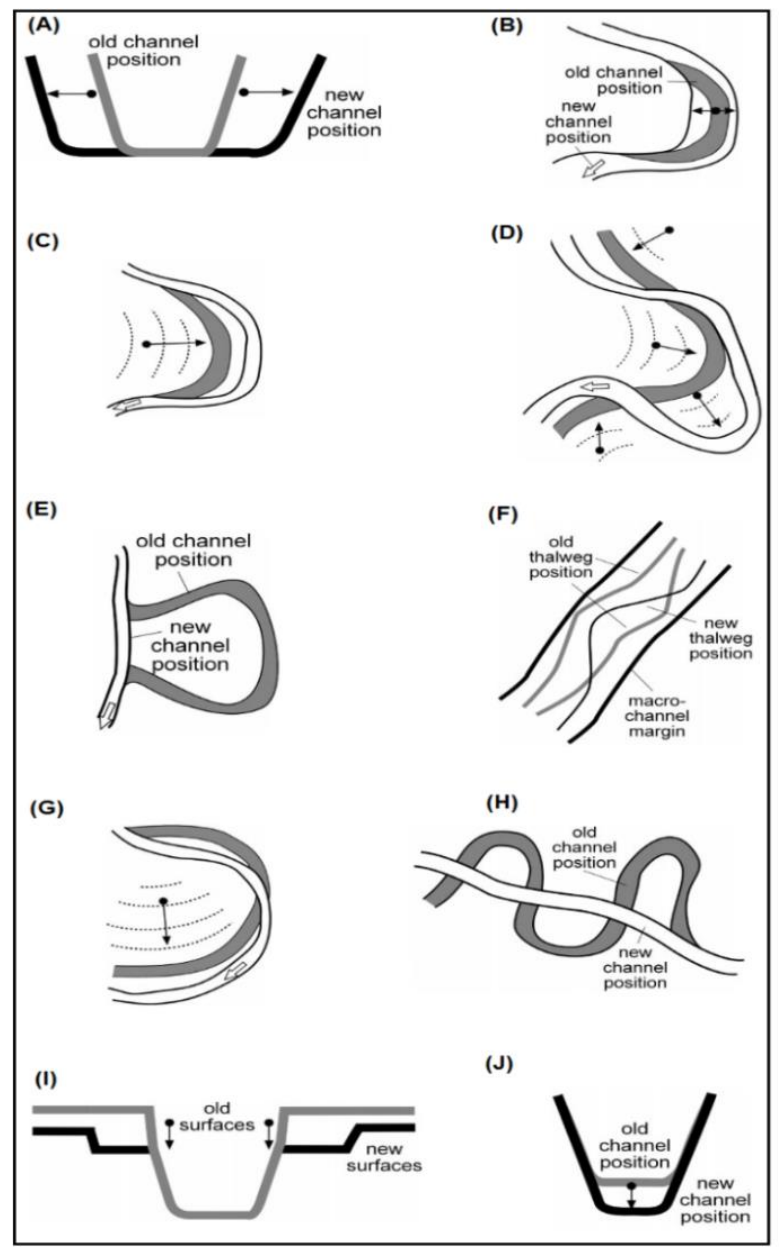

Figura 03 - Tipos de ajustes fluviais: (A) Expansão do canal; (B) Dimensão Lateral (Largura); (C) Extensão da Curvatura; (D) Rotação da Curva; (E) Interrupções; (F) Realinhamento do baixo fluxo do canal; (G) Translação da curva; (H) Retilinização ou Retificação; (I) Desnudamento da várzea; (J) Dimensão Vertical Fonte: Fryirs et al., (2009).

As fotografias aéreas utilizadas neste mapeamento foram disponibilizadas pela Secretaria do Meio Ambiente e Recursos Hídricos do Paraná, para os anos de 1954 e 1980 (escala 1:25.000), enquanto que as fotografias de 1996 foram cedidas pela empresa Engefoto (escala 1:30.000). As imagens de satélite correspondem a uma SPOT-5 (2006), e uma RapidEye (2012), ambas pancromáticas, com resolução espacial de cinco metros.

Para identificar os locais com maior concentração de erosão, ou seja, as margens fluviais que mais sofreram com os processos erosivos, utilizaram-se das hidrografias principais mapeadas para os anos de 1954 e 2012, por se tratar da primeira e da última imagem aérea obtida para essa pesquisa. Foram escolhidas três seções (por terço de rio) que apresentaram maiores mudanças visuais, medindo-se a distância de expansão entre a margem fluvial esquerda e direita, para os dois anos abordados. Apenas as seções que apresentaram mais de cinco metros de alargamento foram classificadas como áreas com concentração de erosão, definida de acordo com as escalas das imagens citadas acima.

A última fase da etapa 1 da metodologia refere-se à conectividade fluvial, muito importante na determinação da sensitividade, pois indica se mudanças pontuais na bacia poderão se propagar em outras direções. A classificação da conectividade baseou-se em Hooke (2003), descrita como: conectada, quando não há impedimentos entre a transmissão de 


\section{SENSITIVIDADE FLUVIAL DA DRENAGEM PRINCIPAL DA BACIA HIDROGRÁFICA DO RIO SAGRADO - SERRA DO MAR PARANAENSE}

matéria (sedimentos) e energia (água); parcialmente conectada, há um impedimento, mas a conexão do sistema não é interrompida; e não conectado, caracterizado por um impedimento que interrompe por completo a transmissão de matéria e energia.

A conectividade foi estabelecida por meio de interpretação das imagens de satélite, com a identificação dos sedimentos depositados, além dos trabalhos de campo realizados nos anos de 2013, 2014 e 2016.

A etapa 2 consistiu na sobreposição de cada dado da etapa 1 com o uso da terra na bacia, a fim de verificar a relação entre a proximidade das alterações em sua ocupação com as mudanças fluviais encontradas na etapa anterior. Para isso, tornou-se necessário estudar a evolução dos usos e ocupações da terra, mapeados por Kleina (2016), para os anos de 1954, 1980, 1996, 2006 e 2012, na escala 1:25.000, abrangendo áreas homogêneas, como vegetação em estágio médio e avançado (nível 1); vegetação em estágio inicial (nível 2); pastagens e campos (nível 3); atividades antrópicas não agricultáveis, como estradas, residências e solo exposto (nível 4) e atividades antrópicas agrícolas (nível 5).

Ressalta-se que as modificações no uso e ocupação da terra foram trabalhadas em sua totalidade na bacia, contudo, foi dado enfoque nos arredores dos eixos fluviais. Nesta etapa, os dados dos ajustes, estilos e concentração de erosão foram sobrepostos com a ocupação da terra, verificando a proximidade das alterações em seu uso com as transformações no sistema fluvial, como por exemplo, rios margeados por áreas antrópicas agrícolas possuem grande potencial de alterações fluviais aceleradas, devido a erosão causada pelo solo exposto, diferentemente daquelas que detêm de matas ciliares preservadas, rodeadas por vegetação em estágio médio e avançado.

A etapa 3 consistiu na classificação da sensitividade, de acordo com as resistências e perturbações na paisagem e que afetam o sistema fluvial. Deste modo, áreas transformadas de nível 1 para nível 2, próximos às drenagens resistentes, foram consideradas pouco perturbadas e de baixa sensitividade. Modificações de nível 1 e 2 para nível 3 foram classificadas como moderada sensitividade; e mudanças de níveis 1,2 e 3 modificados para o 4 e 5 , próximos a elevados ajustes fluviais, foram considerados rios pouco resistentes e muito perturbados, de alta sensitividade.

A classificação da sensitividade foi adaptada conforme as características do uso e ocupação da bacia descritas anteriormente, juntamente com as alterações fluviais encontradas na primeira etapa, seguindo a proposta de Souza (2014), descritas a seguir:

Alta sensitividade: segmentos de drenagens próximos ao uso e ocupação da terra em níveis 4 e 5 , assim como margens fluviais erosivas e com acúmulo de sedimentos, que proporcionam mudanças na sinuosidade, geram grande quantidade de ajustes fluviais e que necessitam de intervenções imediatas para recuperação da paisagem;

Moderada sensitividade: média probabilidade de ocorrências de erosões e mudanças na paisagem, como declividades fluviais moderadas, poucos ajustes e pequenas alterações no uso e ocupação da terra (níveis 1 e 2 para nível 3);

Baixa sensitividade: ocorrência reduzida ou baixa probabilidade de transformações na paisagem, como áreas sem a presença de ajustes fluviais; leito e margens fluviais rochosas (determinado pelos EFs); cursos fluviais margeados por vegetação geral em estágio médio ou avançado e poucas intervenções antrópicas (níveis 1 e 2).

\section{RESULTADOS E DISCUSSÃO}

Os Estilos Fluviais reúnem as características morfológicas dos principais rios da bacia, apresentado na Tabela 1 e Figura 4. Estes dados revelam que o maior afluente da bacia, o rio Sambaqui é aquele que detêm a maior quantidade de EFs, superando o próprio rio principal (rio Sagrado) que possui sete diferentes estilos (KLEINA, et al., 2014). 
KLEINA, M. e SANTOS, L.J.C.

\section{SENSITIVIDADE FLUVIAL DA DRENAGEM PRINCIPAL DA BACIA HIDROGRÁFICA DO RIO SAGRADO - SERRA DO MAR PARANAENSE}

Tabela 01 - Estilos Fluviais da rede de drenagem principal da bacia do rio Sagrado

\begin{tabular}{|c|c|c|c|c|}
\hline Rio & Estilo Fluvial & Tipo de Vale & $\begin{array}{c}\text { Declividade da } \\
\text { Vertente }\end{array}$ & $\begin{array}{l}\text { Feições } \\
\text { Fluviais }\end{array}$ \\
\hline \multirow{7}{*}{ 을 } & Sinuoso de vale confinado & Confinado & $\begin{array}{c}\text { Muito alta (acima de } \\
47 \%)\end{array}$ & - \\
\hline & $\begin{array}{c}\text { Sinuoso de vale } \\
\text { parcialmente confinado }\end{array}$ & $\begin{array}{c}\text { Parcialmente } \\
\text { confiando }\end{array}$ & $\begin{array}{c}\text { Alta a moderada (47 a } \\
12 \%) \\
\end{array}$ & - \\
\hline & $\begin{array}{c}\text { Canal irregular sem } \\
\text { deposição }\end{array}$ & $\begin{array}{l}\text { Parcialmente } \\
\text { confinado }\end{array}$ & $\begin{array}{c}\text { Alta a moderada (47 a } \\
12 \%)\end{array}$ & - \\
\hline & $\begin{array}{l}\text { Meandros irregulares com } \\
\text { deposição }\end{array}$ & Não confiando & $\begin{array}{l}\text { Baixa a muito baixa } \\
\text { (12 a menos que } 5 \%)\end{array}$ & $\begin{array}{l}\text { Ilhas e } \\
\text { barras } \\
\text { (recentes) }\end{array}$ \\
\hline & $\begin{array}{l}\text { Meandros tortuosos com } \\
\text { deposição }\end{array}$ & Não confinado & $\begin{array}{l}\text { Baixa a muito baixa } \\
(12 \text { a menos que } 5 \%)\end{array}$ & $\begin{array}{c}\text { Ilhas e } \\
\text { barras } \\
\text { (recentes) }\end{array}$ \\
\hline & Retificado com deposição & Não confinado & $\begin{array}{l}\text { Baixa a muito baixa } \\
\text { (12 a menos que } 5 \%)\end{array}$ & $\begin{array}{l}\text { Ilhas e } \\
\text { barras } \\
\text { (recentes) }\end{array}$ \\
\hline & Retificado sem deposição & Não confinado & $\begin{array}{l}\text { Baixa a muito baixa } \\
\text { (12 a menos que } 5 \% \text { ) }\end{array}$ & - \\
\hline \multirow{8}{*}{$\begin{array}{l}\bar{\Xi} \\
\text { бू̆ } \\
\text { है } \\
\text { ळึ }\end{array}$} & Sinuoso de vale confinado & Confinado & $\begin{array}{c}\text { Muito alta (acima de } \\
47 \%)\end{array}$ & - \\
\hline & $\begin{array}{l}\text { Sinuoso de vale } \\
\text { parcialmente confinado }\end{array}$ & $\begin{array}{c}\text { Parcialmente } \\
\text { confinado }\end{array}$ & $\begin{array}{c}\text { Muito alta a alta } \\
\text { (acima de } 47 \text { a } 30 \% \text { ) }\end{array}$ & - \\
\hline & $\begin{array}{l}\text { Canal irregular sem } \\
\text { deposição }\end{array}$ & $\begin{array}{l}\text { Parcialmente } \\
\text { confinado }\end{array}$ & $\begin{array}{c}\text { Muito alta a alta } \\
\text { (acima de } 47 \text { a } 30 \% \text { ) }\end{array}$ & - \\
\hline & $\begin{array}{l}\text { Canal irregular com } \\
\text { deposição }\end{array}$ & Não confinado & $\begin{array}{c}\text { Moderada a muito } \\
\text { baixa ( } 30 \text { a menos } \\
\text { que } 5 \% \text { ) }\end{array}$ & $\begin{array}{l}\text { Ilhas e } \\
\text { barras } \\
\text { (recentes) }\end{array}$ \\
\hline & Sinuoso sem deposição & Não confinado & $\begin{array}{c}\text { Moderada a muito } \\
\text { baixa ( } 30 \text { a menos } \\
\text { que } 5 \% \text { ) }\end{array}$ & P \\
\hline & $\begin{array}{l}\text { Meandros irregulares com } \\
\text { deposição }\end{array}$ & Não confinado & $\begin{array}{c}\text { Muito baixa } \\
\text { (menos que } 5 \% \text { ) }\end{array}$ & $\begin{array}{c}\text { Barras } \\
\text { (recentes) }\end{array}$ \\
\hline & Sinuoso com deposição & Não confinado & $\begin{array}{c}\text { Muito baixa } \\
\text { (menos que } 5 \% \text { ) }\end{array}$ & $\begin{array}{l}\text { Ilhas e } \\
\text { barras } \\
\text { (recentes) }\end{array}$ \\
\hline & Sinuoso sem deposição & Não confinado & $\begin{array}{c}\text { Muito baixa } \\
\text { (menos que } 5 \% \text { ) }\end{array}$ & - \\
\hline \multirow{2}{*}{ 욤 } & $\begin{array}{l}\text { Meandros irregulares com } \\
\text { deposição }\end{array}$ & Não confinado & $\begin{array}{c}\text { Muito baixa } \\
\text { (menos que } 5 \%)\end{array}$ & $\begin{array}{l}\text { llhas e } \\
\text { barras }\end{array}$ \\
\hline & Sinuoso sem deposição & Não confinado & $\begin{array}{c}\text { Muito baixa } \\
\text { (menos que } 5 \% \text { ) }\end{array}$ & - \\
\hline \multirow{3}{*}{ 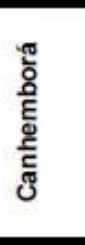 } & Sinuoso de vale confinado & Confinado & $\begin{array}{c}\text { Muito alta a alta } \\
\text { (acima de } 47 \text { a } 30 \% \text { ) }\end{array}$ & - \\
\hline & $\begin{array}{l}\text { Canal irregular de vale } \\
\text { parcialmente confinado }\end{array}$ & $\begin{array}{l}\text { Parcialmente } \\
\text { confinado }\end{array}$ & $\begin{array}{c}\text { Alta a moderada (47 a } \\
12 \%)\end{array}$ & - \\
\hline & $\begin{array}{l}\text { Canal irregular de vale não } \\
\text { confinado }\end{array}$ & Não confinado & $\begin{array}{c}\text { Baixa a muito baixa ( } 12 \\
\text { a menos que } 5 \% \text { ) }\end{array}$ & - \\
\hline \multirow{2}{*}{ 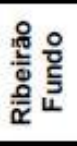 } & Sinuoso de Vale Confinado & Confinado & $\begin{array}{c}\text { Muito alta (acima de } \\
47 \% \text { ) }\end{array}$ & - \\
\hline & $\begin{array}{l}\text { Sinuoso de vale parcialmente } \\
\text { confinado }\end{array}$ & $\begin{array}{l}\text { Parcialmente } \\
\text { confinado }\end{array}$ & $\begin{array}{c}\text { Alta a moderada (47 a } \\
12 \%) \\
\end{array}$ & - \\
\hline ฐ & $\begin{array}{l}\text { Canal irregular de vale não } \\
\text { confinado }\end{array}$ & Não confinado & $\begin{array}{c}\text { Moderada a muito } \\
\text { baixa (30 a menos que } \\
5 \% \text { ) }\end{array}$ & - \\
\hline
\end{tabular}

Fonte: Os autores

Lima (2010) destaca a importância da classificação de drenagens por meio dos EFs, utilizada na compreensão do potencial de cada rio, como por exemplo, identificar canais instáveis, canais propensos à migração lateral ou sensíveis às mudanças no uso e ocupação da terra, assim como registrado para os principais rios da bacia, com a formação de feições fluviais 


\section{SENSITIVIDADE FLUVIAL DA DRENAGEM PRINCIPAL DA BACIA HIDROGRÁFICA DO RIO SAGRADO - SERRA DO MAR PARANAENSE}

de depósito, localizadas principalmente em estilos meandrantes (KLEINA, et al., 2014).

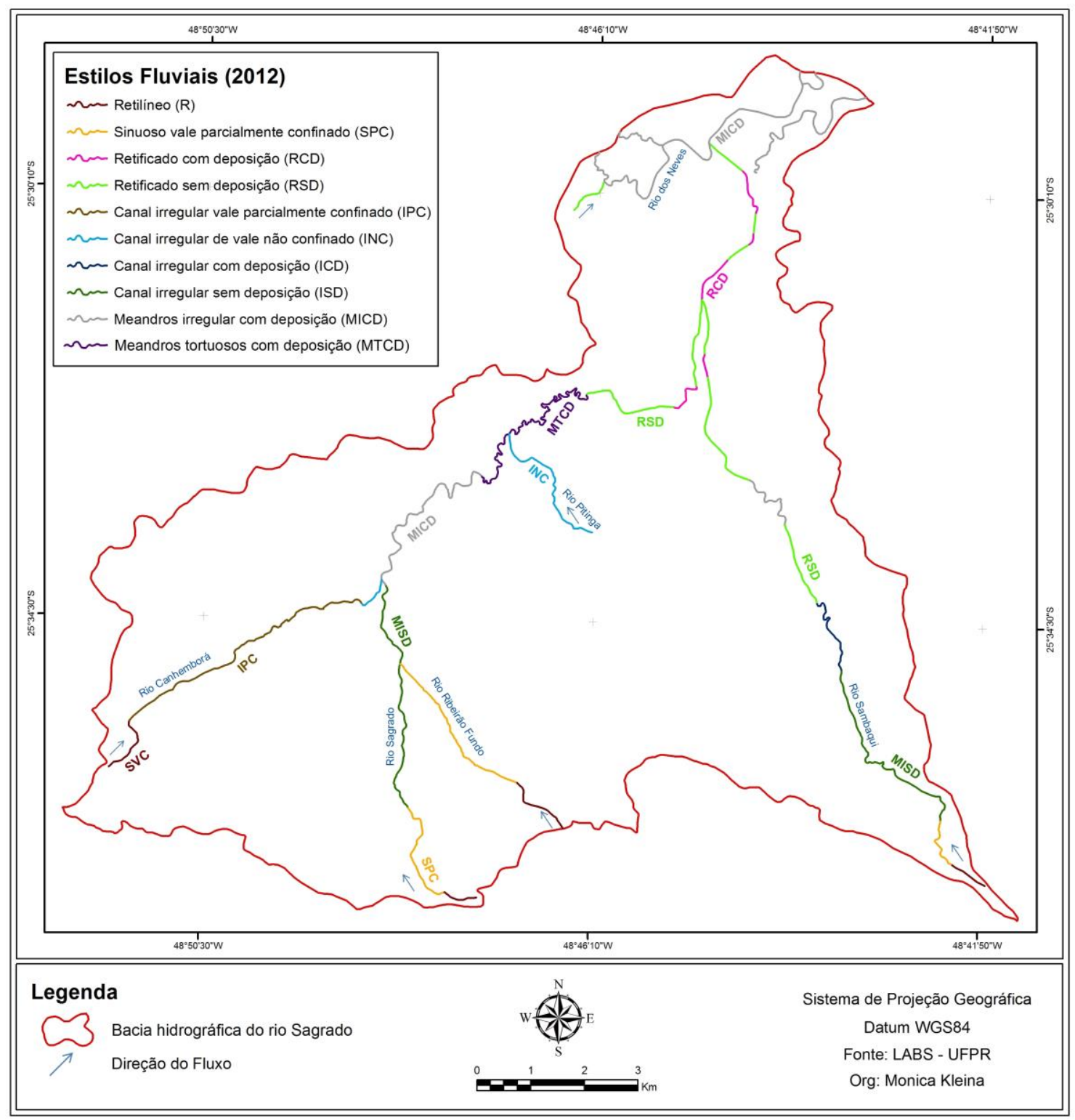

Figura 04 - Estilos Fluviais da rede de drenagem principal do rio Sagrado. Fonte: Os autores

No que se referem aos ajustes fluviais, os resultados indicam que a retilinização é o mais frequente (Figura 5), seguido da dimensão lateral, representada pela Figura 6. Somente dois EFs não apresentaram ajustes, denominados retilíneo e sinuoso de vale parcialmente confinado, ambos pertencentes ao terço superior. Predominam altas declividades, leitos rochosos, pouca erosão e nenhuma deposição, não exibindo variações significativas a ponto de apresentarem algum tipo de ajustamento. 


\section{SENSITIVIDADE FLUVIAL DA DRENAGEM PRINCIPAL DA BACIA HIDROGRÁFICA DO RIO SAGRADO - SERRA DO MAR PARANAENSE}

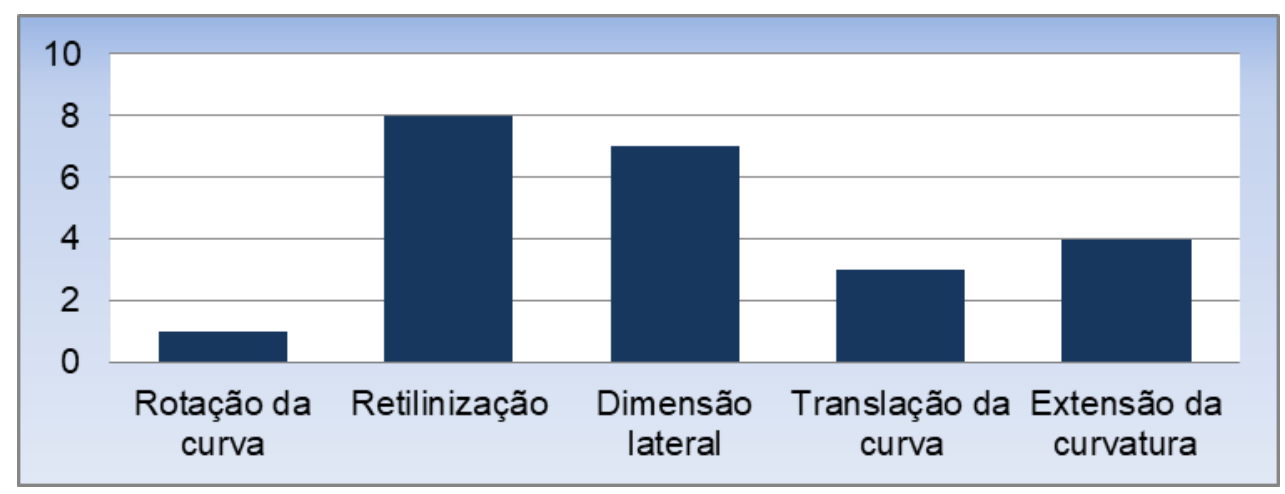

Figura 05 - Quantificação dos tipos de ajustes fluviais identificados na rede de drenagem principal do rio Sagrado nos anos de 1954 e 2012. Fonte: Os autores

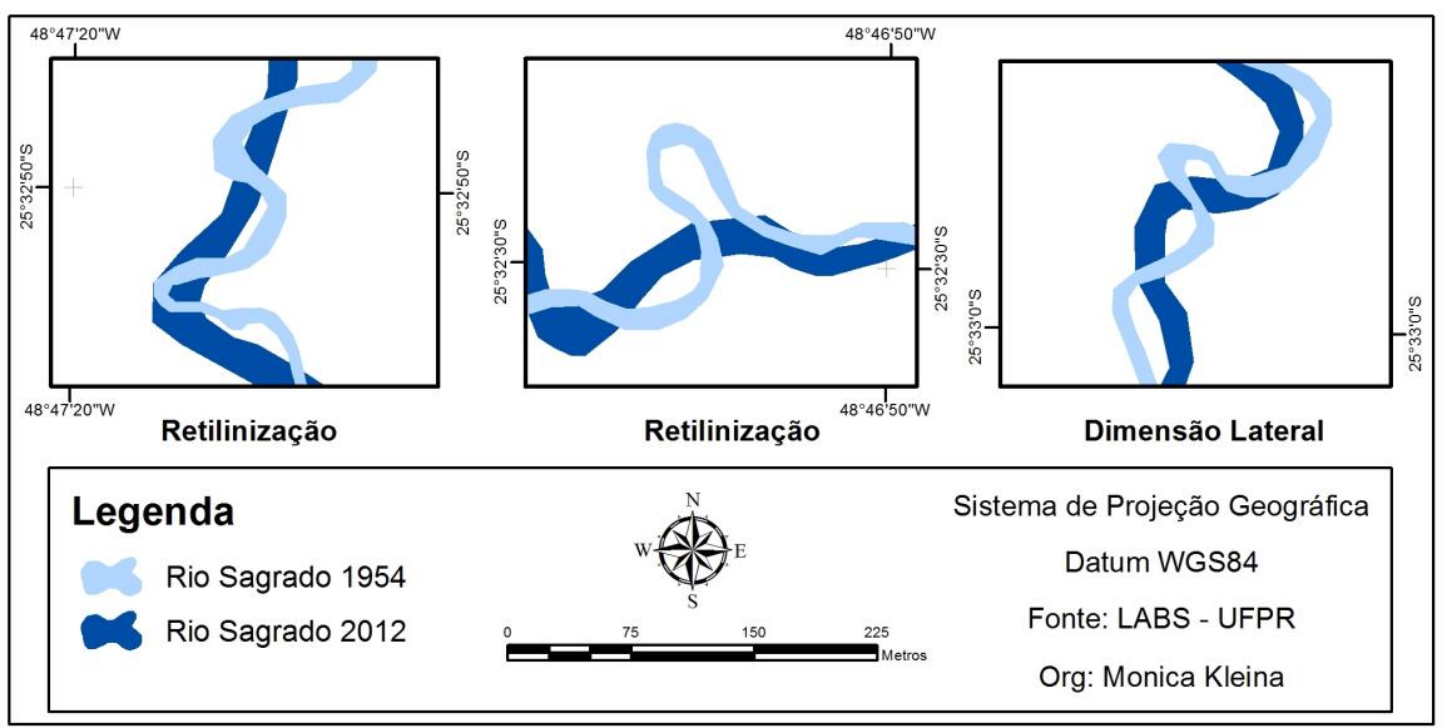

Figura 06 - Ajustes identificados no EF meandros tortuosos com deposição no rio Sagrado. Fonte: Os autores.

As áreas com concentração de erosão correspondem às seções fluviais que apresentaram mais do que cinco metros de expansão, de 1954 a 2012. Os maiores valores de concentração de erosão foram detectados próximos à foz do rio dos Neves, área localizada na planície litorânea e que sofre constantemente com a influência da maré, com valores que ultrapassam quinze metros de ampliação, em uma seção, entre a margem fluvial direita e esquerda. Para Farias (1997), canais influenciados pela maré constituem a zona de maior energia hidráulica do sistema, responsável pelo carregamento e deposição de sedimentos, assoreando a planície e originando barras arenosas.
Outros segmentos com maiores concentrações de erosões correspondem aos terços médio dos rios Sambaqui e Sagrado e ainda o inferior deste último, com seção pontual de até nove metros de expansão, diferentemente dos menores afluentes (Canhemborá, Ribeirão Fundo e Pitinga) que expandiram sua largura em somente um metro.

A Tabela 2 apresenta a conectividade do sistema fluvial na bacia segundo seus EFs e a possível conexão com a ocorrência de eventos extremos (pluviosidade elevada). Precipitações como ocorridas em março de 2011 podem transportar excessivo volume de sedimentos, movendo as feições fluviais de depósito, alterando a conexão do sistema. 
KLEINA, M. e SANTOS, L.J.C.

\section{SENSITIVIDADE FLUVIAL DA DRENAGEM PRINCIPAL DA BACIA HIDROGRÁFICA DO RIO SAGRADO - SERRA DO MAR PARANAENSE}

Tabela 02 - Conectividade segundo os Estilos Fluviais

\begin{tabular}{|c|c|c|c|}
\hline Rio & $\begin{array}{l}\text { Estilo } \\
\text { Fluvial }\end{array}$ & Conectividade & Características \\
\hline \multirow{7}{*}{ Sagrado } & $\mathrm{R}$ & Conectado & \multirow{7}{*}{$\begin{array}{c}\text { Altas declividades e leito rochoso } \\
\text { proporcionam conectividade nos três } \\
\text { primeiros E.F., porém à medida que se } \\
\text { iniciam os processos de deposição, a } \\
\text { conectividade torna-se parcial, na qual as } \\
\text { feições estreitam o canal fluvial e podem } \\
\text { prejudicar a transmissão de matéria e } \\
\text { energia. } \\
\text { OBS: se ocorrer um evento extremo todo o } \\
\text { rio poderá se conectar }\end{array}$} \\
\hline & SPC & Conectado & \\
\hline & MISD & Conectado & \\
\hline & MICD & $\begin{array}{c}\text { Parcialmente } \\
\text { conectado }\end{array}$ & \\
\hline & MTCD & $\begin{array}{l}\text { Parcialmente } \\
\text { conectado }\end{array}$ & \\
\hline & $\mathrm{RSD}$ & $\begin{array}{l}\text { Parcialmente } \\
\text { conectado }\end{array}$ & \\
\hline & $\mathrm{RCD}$ & $\begin{array}{c}\text { Parcialmente } \\
\text { conectado }\end{array}$ & \\
\hline \multirow{7}{*}{ Sambaqui } & $\bar{R}$ & Conectado & \multirow{7}{*}{$\begin{array}{l}\text { Altas declividades, pouca sinuosidade e } \\
\text { leito rochoso proporcionam conectividade } \\
\text { nos três primeiros E.F. A partir da formação } \\
\text { das feições no segmento irregular com } \\
\text { deposição, o canal torna-se parcialmente } \\
\text { conectado, com características } \\
\text { semelhantes ao do rio Sagrado. } \\
\text { OBS: se ocorrer um evento extremo todo o } \\
\text { rio poderá se conectar }\end{array}$} \\
\hline & SPC & Conectado & \\
\hline & ISD & Conectado & \\
\hline & $I C D$ & $\begin{array}{l}\text { Parcialmente } \\
\text { conectado }\end{array}$ & \\
\hline & $\mathrm{RSD}$ & $\begin{array}{l}\text { Parcialmente } \\
\text { conectado }\end{array}$ & \\
\hline & MICD & $\begin{array}{l}\text { Parcialmente } \\
\text { conectado }\end{array}$ & \\
\hline & $\mathrm{RCD}$ & $\begin{array}{l}\text { Parcialmente } \\
\text { conectado }\end{array}$ & \\
\hline \multirow[t]{2}{*}{ dos Neves } & RSD & $\begin{array}{l}\text { Parcialmente } \\
\text { conectado }\end{array}$ & \multirow{2}{*}{$\begin{array}{l}\text { Extensas barras arenosas tornam o canal } \\
\text { parcialmente conectado. } \\
\text { OBS: mesmo com a presença de eventos } \\
\text { extremos, o canal continuará parcialmente } \\
\text { conectado, devido à presença de estradas } \\
\text { rurais e algumas barras estáveis com } \\
\text { cobertura vegetal } \\
\end{array}$} \\
\hline & MICD & $\begin{array}{l}\text { Parcialmente } \\
\text { conectado }\end{array}$ & \\
\hline \multirow{3}{*}{ Canhemborá } & $\mathrm{R}$ & Conectado & \multirow{3}{*}{$\begin{array}{c}\text { Tributário conectado com o rio principal. } \\
\text { Não há barreiras que impeçam a } \\
\text { transmissão de matéria e energia, ou seja, } \\
\text { está conectado. } \\
\text { OBS: Mesmo durante períodos menos } \\
\text { chuvosos, o rio continuará conectado }\end{array}$} \\
\hline & IPC & Conectado & \\
\hline & INC & Conectado & \\
\hline \multirow{2}{*}{$\begin{array}{l}\text { Ribeirão } \\
\text { Fundo }\end{array}$} & $\mathrm{R}$ & Conectado & \multirow{2}{*}{$\begin{array}{l}\text { Tributário conectado com o rio principal e } \\
\text { conectado com as encostas. } \\
\text { OBS: Mesmo durante períodos menos } \\
\text { chuvosos, o rio continuará conectado }\end{array}$} \\
\hline & SPC & Conectado & \\
\hline Pitinga & INC & $\begin{array}{l}\text { Parcialmente } \\
\text { conectado }\end{array}$ & $\begin{array}{l}\text { Tributário conectado com o rio principal, } \\
\text { porém a baixa declividade e formação da } \\
\text { planície de inundação torna-o parcialmente } \\
\text { conectado. } \\
\text { OBS: se ocorrer um evento extremo todo o } \\
\text { rio poderá se conectar }\end{array}$ \\
\hline
\end{tabular}

Fonte: Os autores

A evolução temporal do uso da terra na bacia comprova o crescimento das áreas agricultáveis de 1954 para 2012 (Tabela 3), o que confirma a baixa resistência para mudanças neste tipo de paisagem. 
KLEINA, M. e SANTOS, L.J.C.

\section{SENSITIVIDADE FLUVIAL DA DRENAGEM PRINCIPAL DA BACIA HIDROGRÁFICA DO RIO SAGRADO - SERRA DO MAR PARANAENSE}

Tabela 03 - Uso e ocupação da terra na bacia do rio Sagrado dividido por classes

\begin{tabular}{c|c|c|c|c|c}
\cline { 2 - 6 } & \multicolumn{5}{c}{ Classe $\left(\mathbf{K m}^{2}\right)$} \\
\hline Ano & $\begin{array}{c}\text { Vegetação } \\
\text { Médio/Avançado }\end{array}$ & $\begin{array}{c}\text { Vegetação } \\
\text { Inicial }\end{array}$ & $\begin{array}{c}\text { Campos e } \\
\text { Pastagens }\end{array}$ & $\begin{array}{c}\text { Areas antrópicas } \\
\text { agricultáveis }\end{array}$ & $\begin{array}{c}\text { Areas antrópicas não } \\
\text { agricultáveis }\end{array}$ \\
\hline $\mathbf{1 9 5 4}$ & 110 & 12,1 & 13,6 & 1,7 & 0,08 \\
\hline $\mathbf{1 9 8 0}$ & 103,6 & 16,1 & 13,9 & 2,3 & 1 \\
\hline $\mathbf{1 9 9 6}$ & 106,2 & 14,9 & 11,6 & 3,7 & 1,2 \\
\hline $\mathbf{2 0 0 6}$ & 110 & 7,4 & 11,9 & 6,7 & 1,4 \\
\hline $\mathbf{2 0 1 2}$ & 111 & 6,1 & 8,4 & 6,8 & 1,5 \\
\hline
\end{tabular}

Fonte: Os autores

Por meio da análise da evolução do uso e ocupação da terra, percebe-se que novas áreas antrópicas surgiram, responsáveis pela formação acelerada de erosões, ajustes e feições de depósito, principalmente no rio Sagrado. Isso condiz com a afirmação de Paula (2010), que aponta a elevada quantidade de sedimentos produzida pela bacia, uma das responsáveis pelo assoreamento da baía de Antonina.

A Figura 7 retrata o mapeamento da sensitividade fluvial para as principais drenagens da bacia hidrográfica do rio Sagrado. Nas porções sudoeste, sul e sudeste da bacia, próximas as encostas da Serra do Mar paranaense, encontram-se as áreas com maior resistência da bacia, sem ajustes fluviais e concentração de erosão, além de poucas modificações no uso e ocupação da terra, atualmente coberto principalmente por vegetação em estágio médio e avançado (Floresta Ombrófila Densa), denominadas como baixa sensitividade. 


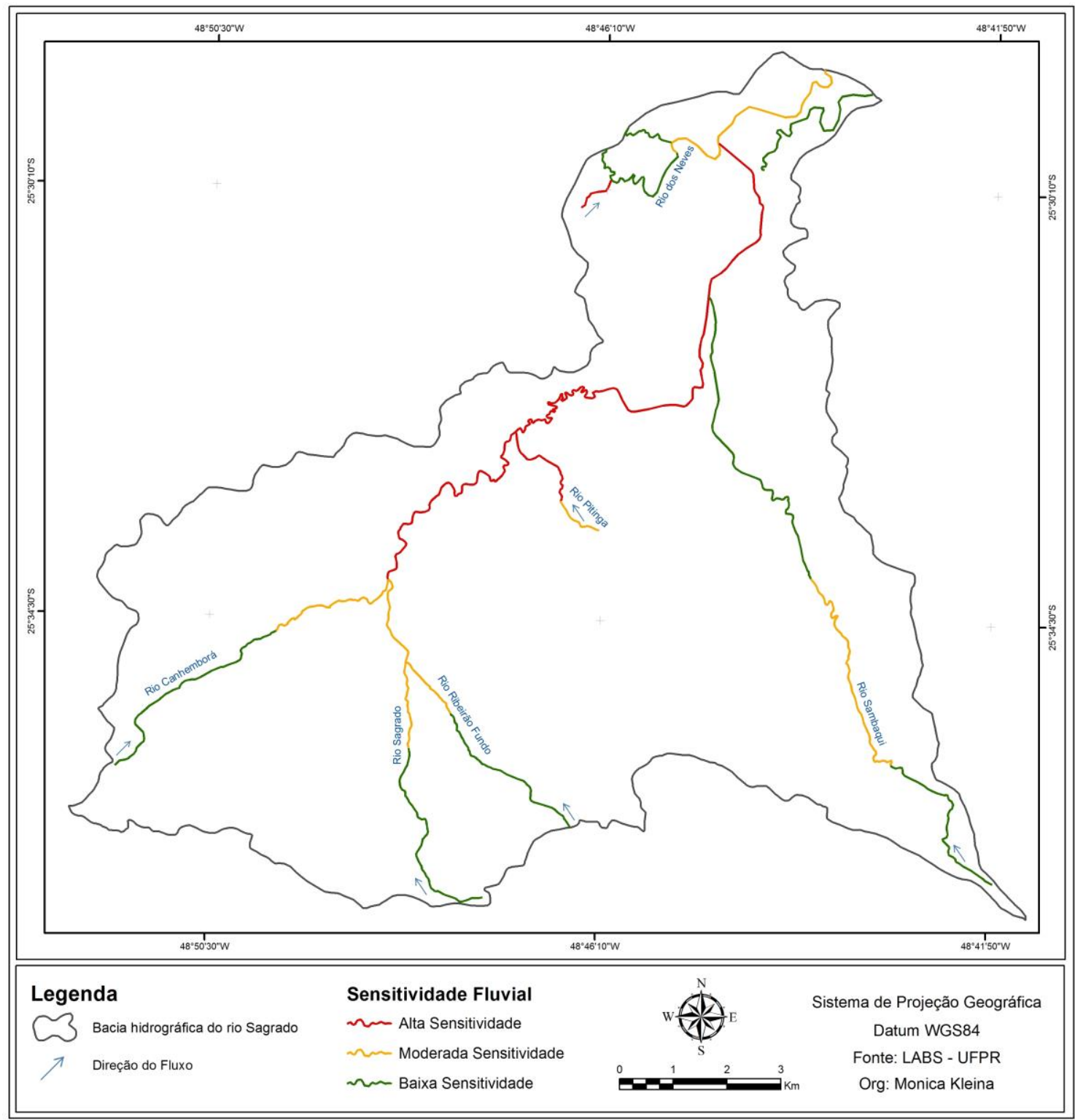

Figura 07 - Sensitividade Fluvial na bacia do rio Sagrado. Fonte: Os autores

A Área de Preservação Permanente (APP) de mata ciliar, próxima a confluência dos rios Sagrado e Sambaqui foi à região mais afetada pelas perturbações, onde em 1954 era ocupada por vegetação em estágio médio e atualmente é usada para a agricultura. A baixa resistência desta paisagem, aliada ao elevado número de ajustes fluviais classifica seus terços inferiores como de alta sensitividade, necessitando de reabilitações e intervenções imediatas para sua reabilitação.

No rio dos Neves há poucas probabilidades de alterações significativas no uso e ocupação da terra, pois corresponde a uma área de difícil acesso, constantemente alagada, contudo a influência da maré é a grande responsável pela elevada carga de sedimentos transportados, classificando-a como de baixa à moderada sensitividade.

\section{CONCLUSÃO}

As formações de feições de depósito em rios, próximas as áreas com uso e ocupação da terra desprotegidos, indicam alterações aceleradas na paisagem, provocadas pela baixa resistência neste tipo de ambiente, assim como vem ocorrendo principalmente próximo as planícies dos rios Sagrado e Sambaqui. Estas feições são instáveis, de formação recente, e apesar de muitas estreitarem o fluxo de água entre uma margem fluvial e outra, não podem ser consideradas barreiras que possam interromper a conectividade do sistema. 


\section{SENSITIVIDADE FLUVIAL DA DRENAGEM PRINCIPAL DA BACIA HIDROGRÁFICA DO RIO SAGRADO - SERRA DO MAR PARANAENSE}

A alta sensitividade foi detectada nos segmentos que apresentaram grandes alterações após a aplicação de uma força de perturbação. Estas áreas se caracterizaram pela presença de ajustes fluviais, retificação de alguns terços inferiores, apresentada pelos EFs, além da erosão gradativa. A causa para essas mudanças fluviais relaciona-se principalmente pelas transformações no uso e ocupação da terra próximo aos eixos fluviais, com expansão da agricultura, que desprotege continuamente o solo, proporcionando a erosão acelerada e consequentemente a produção de sedimentos para os canais.

A morfologia dos terços superiores das principais drenagens da bacia hidrográfica do rio Sagrado não apesenta mudanças significativas, com poucas erosões e poucas variações na sinuosidade, o que determina a alta resistência da paisagem. $O$ uso e ocupação da terra permanece praticamente intocado nas regiões de serras, o que favorece a baixa sensitividade fluvial nesta região.

Os resultados permitiram 0 reconhecimento dos pontos mais sensíveis às mudanças, tornando possível identificar as áreas que necessitam de intervenções imediatas para recuperação da degradação, ou seja, aquelas mais perturbadas, pouco resistentes e de alta sensitividade.

\section{REFERÊNCIAS}

ABDON, M. M. Os impactos ambientais no meio físico - erosão e assoreamento na bacia hidrográfica do rio Taquari, MS, em decorrência da pecuária. 2004. Dissertação (Tese em Engenharia Ambiental). Escola de Engenharia de São Carlos da Universidade de São Paulo, São Paulo.

AB'SABER, A. N. Os terraços fluviais da região de São Paulo. Boletim Geográfico, v. 15, p. 45-47, 1957.

BAYER, M.; CARVALHO, T. M. Processos morfológicos e sedimentos no canal do rio Araguaia. Revista de Estudos Ambientais.v.10. n. 2, p. 24-31. 2008.

BERNARD, H. A.; MAJOR, C. F. Recent meander belt deposits of the Brazos River: an alluvial sand model. Bull American Assoc. Petroleum Geologists, v. 47, 1963.
BIGARELLA, J. J.; MOUSINHO, M. R. Considerações a respeito dos terraços fluviais, rampas de colúvio e várzeas. Boletim Paranaense de Geografia, v.16/17, p. 153-197, 1965.

BRIERLEY, G.; FRYIRS, K. A. Application of the River Styles framework as a basis for river management in New South Wales, Australia. Applied Geography, v. 22, p. 91-122, 2002.

BRIERLEY, G. J.; FRYIRS, K. A. Geomorphology and River Management: Applications of the River Styles Framework. Blackwell Publishing, Oxford, UK, 2005.

BRUNSDEN, D. Barriers to geomorphological change. In Thomas, D.S.G. and Allison, R. J. Landscape Sensitivity. Wiley e Sons, p. 7-12, 1993.

BRUNSDEN, D. Geomorphological events and landform change. Zeitschrift für Geomorphologie, v. 40, p. $273-288,1996$.

BRUNSDEN, D. A critical assessment of the sensitivity concept in Geomorphology. Catena, v. 42, p. 99-123, 2001.

BRUNSDEN, D.; THORNES, J. B. Landscape sensitivity and change. Transactions of the Institute of British Geographers, n. 4, p. 463-484, 1979.

CARVALHO, T. M. Avaliação do transporte de carga sedimentar no médio rio Araguaia. Revista Geosul, v. 24. n. 47, p. 147-160, 2009.

CHORLEY, R. J.; KENNEDY, B. A. Physical Geography: A Systems Approach. London: Prentice Hall, 1971.

CHRISTOFOLETTI, A. Análise morfométrica de bacias hidrográficas. Notícia Geomorfológica, v. 18, n. 9, p. 35-64, 1969.

COLEMAM, J. M.; GAGLIANO, S. M. Sedimentary structures: Mississipi river deltaic plain. Publicação especial no 12 da Soc. Econ. Paleontologists Mineralogists, p. 133-148, 1965.

DAVIS, W. M. The rivers and valleys of Pennsylvania. National Geographic Magazine, v. 7, p. 183-253, 1889.

FARIAS, P. R. C. Geologia de Superfície da Área de Detalhe de Macau-RN. Relatório Final PETROBRÁS/GEXP/GELAB, 1997.

FERNANDEZ, O. V. Q. Mudanças no canal fluvial do rio Paraná e processos de erosão nas 


\section{SENSITIVIDADE FLUVIAL DA DRENAGEM PRINCIPAL DA BACIA HIDROGRÁFICA DO RIO SAGRADO - SERRA DO MAR PARANAENSE}

margens: Região de Porto Rico-PR. 1990. Dissertação (Mestrado), IGCE/UNESP, Rio Claro.

FONTES, L. C. S. Erosão marginal associada a impactos ambientais a jusante de grandes barragens: O caso do baixo curso do rio São Francisco. 2002. Dissertação (Mestrado) Programa de Pós-graduação em Desenvolvimento e Meio Ambiente (PRODEMA), Universidade Federal de Sergipe (UFS), São Cristóvão.

FRYIRS, K. A.; SPINK, A.; BRIERLEY, G. J. PostEuropean settlement response gradients of river sensitivity and recovery across the upper Hunter catchment, Australia. Earth Surface Processes and Landforms, v. 34, 897-918, 2009.

HOOKE, J. Coarse sediment connectivity in river channel systems: a conceptual framework and methodology. Geomorphology, v. 56, 2003.

KELLERHALS, R.; CHURCH, M.; BRAY, D. I. Classification and Analysis of river processes. Journal of Hydraulics Division, American Society of Civil Engineers, v.102, p. 813-829, 1976.

KLEINA, M. Sensitividade Fluvial na bacia hidrográfica do rio Sagrado (Morretes/PR). 2016. Dissertação (Mestrado em Geografia). Departamento de Geografia, Setor de Ciências da Terra, Universidade Federal do Paraná, Curitiba.

KLEINA, M.; PAULA, E. V.; SANTOS, L. J. C. Análise comparativa dos Estilos Fluviais do rio Sagrado (Morretes/PR) para os anos de 2006 e 2011. Revista Geografar (UFPR), v. 9, n.1, p. 27-44, 2014.

KLEINA, M.; SANTOS, L. J. C. Estilos Fluviais do rio Sagrado (Morretes/PR): comparação nos anos de 2006 e 2011. In: SEMANA INTEGRADA DE ENSINO, PESQUISA E EXTENSÃO (Painel - 21응 EVINCI), 2013.

LIMA, R. N. S. Conectividade dos ambientes fluviais: implicações para avaliação da sensibilidade do sistema de drenagem da bacia do Rio Macaé (RJ). 2010. Dissertação (Mestrado em Geografia). Departamento de Geografia, Instituto de Geociências, Centro de Ciências Matemáticas e da Natureza, Universidade Federal do Rio de Janeiro, Rio de Janeiro.

MARÇAL, M. S. Análise das mudanças morfológicas em seções transversais ao rio Macaé/RJ. Revista Brasileira de Geomorfologia, v. 14, n. 1, 2013.
MATTOS, S. H. V. L.; PEREZ FILHO, A. Complexidade e Estabilidade em Sistemas Geomorfológicos: uma introdução ao tema. Revista Brasileira de Geomorfologia, v. 5, n. 1, 2004.

MINEROPAR - Minerais do Paraná S. A - (Serviço Geológico do Paraná). Atlas geológico do Estado do Paraná. Curitiba, 2001.

NEWSON, M. D.; LARGE, A. R. G. 'Natural' rivers, 'hydromorphological quality' and river restoration: a challenging new agenda for applied fluvial geomorphology. Earth Surface Processes and Landforms. v. 31, p. 1606-1624, 2006.

OLIVEIRA, C. K. R.; SALGADO, A. A. R. Geomorfologia Brasileira: Panorama Geral da Produção Nacional de Alto Impacto no Quinquênio entre 2006-2010. Revista Brasileira de Geomorfologia, v. 14, p. 117-123, 2013.

PAULA, E. V. Análise da Produção de Sedimentos na Área de Drenagem da Baía de Antonina/PR uma abordagem geopedológica. 2010. Tese (Doutorado em Geografia). Departamento de Geografia, Setor de Ciências da Terra, Universidade Federal do Paraná, Curitiba.

PAULA, E. V.; NOWATZKI, A. Programa de Controle Ambiental das Dragagens de Manutenção dos Portos de Paranaguá e Antonina: 2009. Relatório Parcial. Delimitação das áreas prioritárias à recuperação na bacia hidrográfica do Rio Sagrado (Morretes/PR). Antonina: ADEMADAN, 2009.

PEIXOTO, M. N. O.; CESÁRIO, F. V.; PIMENTEL, M. L.; MELLO, E. V.; OLIVEIRA, D. F. P. Identificação de Estilos de Rios em Bacias de Drenagem inseridas em Compartimentos de Colinas - Médio Vale do rio Paraíba do Sul (RJ). Revista de Geografia (UFPE) - vol. especial VIII SINAGEO, n. 3. Recife, 2010.

PHILLIPS, J. D. Changes, perturbations, and responses in geomorphic systems. Progress in Physical Geography, v. 33, n. 1, p. 17-30, 2009.

RIBEIRO, A. S.; PEIXOTO, M. N. O.; SIQUEIRA, C. Y. S.; TEIXEIRA, C. C.; MOURA, J. R. S.; SÃO THIAGO, A. P. W. Dinâmica Fluvial e Qualidade das Águas em Microbacia Hidrográfica do Município de Volta Redonda (RJ). In: XIX SIMPÓSIO BRASILEIRO DE RECURSOS HÍDRICOS. Alagoas, 2011.

RICE, S. P.; LANCASTER, J.; KEMP, P. Experimentation at the interface of fluvial geomorphology, stream ecology and hydraulic 


\section{SENSITIVIDADE FLUVIAL DA DRENAGEM PRINCIPAL DA BACIA HIDROGRÁFICA DO RIO SAGRADO - SERRA DO MAR PARANAENSE}

engineering and the development of an effective, interdisciplinary river science. Earth Surface Processes and Landforms. v. 35, p. 64-77, 2009.

ROCHA, P. C. Geomorfologia e Conectividade em ambientes fluviais do Alto rio Paraná, Centro-Sul do Brasil. Boletim de Geografia, v. 28, n. 2, p. 157-176, 2010.

SALGADO, A. A. R; BIAZINI, J.; HENNING, S. Geomorfologia brasileira: panorama geral da produção nacional no início do século XXI (20012005). Revista Brasileira de Geomorfologia, v. 9, n. 1, p. 84-91, 2008.

SALGADO, A. A. R.; LIMOEIRO, B. F. Geomorfologia brasileira: panorama geral da produção nacional de alto impacto no quinquênio entre 2011-2015. Nota técnica. Revista Brasileira de Geomorfologia, v. 18, n 1, 2017.

SCHUMM, S. A. River adjustment to altered hydrologic regimen - Murrumbidgee river and paleochannels, Australia. Geological Survey Prof. Paper, p. 1-62, 1968.

SOUZA, J. O. P. Geomorphology and River Management: Applications of the river styles Framework. Victoria: Blackwell publishing (commerce Place, 350 main Street, Malden, MA02148, USA). Resenha. Revista de Geografia (UFPE), 2012.

SOUZA, J. O. P. Modelos de evolução da dinâmica fluvial em ambiente semiárido - bacia do Riacho do Saco, Serra Talhada, Pernambuco. 2014. Tese (Doutorado em Geografia) - Departamento de Ciências Geográficas - DCG, Universidade Federal de Pernambuco, Pernambuco.

SOUZA, J. O. P.; BARROS, A.; CORRÊA, A. C. B. Classificação de canais semiáridos pelo semiárido, bacia do riacho do Saco, Pernambuco. Geonorte, Edição Especial 4, v. 10, n. 1, p. 222227,2014

SOUZA, J. O. P.; CORRÊA, A. C. B. Conectividade e área de captação efetiva de um sistema fluvial semiárido: bacia do riacho Mulungu, Belém de São Francisco - PE. Sociedade \& Natureza, v. 24, n. 2, p. 379-332, 2012.

SOUZA, J. O. P.; CORRÊA, A. C. B. Análise da sensitividade da paisagem na bacia do riacho do Saco - PE. Revista Brasileira de Geomorfologia, v. 16, n. 4, p. 615-630, 2015.

SOUZA MAIA, R., SOUZA, J. O. P. Análise e caracterização em ambiente semiárido dos Estilos
Fluviais na bacia Riacho Jucurutu - PB. In: XI SIMPÓSIO NACIONAL DE GEOMORFOLOGIA. Maringá, 2016.

STEVAUX, J. C. O Rio Paraná: geomorfogênese, sedimentação e evolução quaternária do seu curso superior (região de Porto Rico, PR). 1993. Tese (Doutorado em Geologia) - Departamento de Pós-Graduação em Geologia Sedimentar, Universidade de São Paulo, São Paulo.

ZANCOPÉ, M. H. C.; CARPI JUNIOR, S.; PEREZ FILHO, A. Mudanças no Canal do Rio Mogi Guaçu - Brasil. In: VI SIMPÓSIO NACIONAL DE GEOMORFOLOGIA. Regional Conference on Geomorphology, v. 2, p. 63-63, 2006.

ZANCOPÉ, M. H. C.; CARPI JUNIOR, S.; PEREZ FILHO, A. Migração Fluvial, Pedogênese e Sedimentação na Planície do Rio Mogi Guaçu. In: XII SIMPÓSIO BRASILEIRO DE GEOGRAFIA FÍSICA APLICADA. Natureza, Geotecnologias, Ética e Gestão do Território, v. 1, p. 82-83, 2007. 